\title{
THE PERFORMANCE OF Pt-MODIFIED ALUMINA-FORMING COATINGS AND MODEL ALLOYS
}

\author{
B. A. Pint ${ }^{1}$, J. A. Haynes ${ }^{1}$, K. L. More ${ }^{1}$, J. H. Schneibel ${ }^{1}$, Y. Zhang ${ }^{2}$ and I. G. Wright ${ }^{1}$ \\ ${ }^{1}$ Oak Ridge National Laboratory, Materials Science and Technology Division, Oak Ridge, TN 37831-6156 USA \\ ${ }^{2}$ Tennessee Technological University, Dept. of Mechanical Engineering,Cookeville, TN 38505-0001
}

Keywords: Oxidation resistance, Aluminide coatings, Platinum diffusion coating, Platinum group metals, Yield stress

\begin{abstract}
The oxidation behavior of two-phase, $\gamma+\gamma^{\prime}$ Pt diffusion coatings and model alloys has been evaluated to better understand the potential of this class of coatings for power generation applications. Coatings were deposited on both directionallysolidified alloy 142 and single crystal N5 superalloys. Fabrication issues such as initial Pt thickness and annealing temperature were evaluated. Oxidation testing was performed in both dry $\mathrm{O}_{2}$ and with the addition of $\mathrm{H}_{2} \mathrm{O}$ to study the performance of $\gamma+\gamma^{\prime}$ and conventional coating materials. After exposure for 1000, 1-h cycles at $1150^{\circ} \mathrm{C}$ in dry $\mathrm{O}_{2}$, a $\gamma+\gamma^{\prime}$ coating on $\mathrm{N} 5$ had evolved into a thicker, almost continuous $\gamma$ ' layer with the Pt content dropping to $\sim 7$ at. $\%$ in this layer and diffusing $\sim 250 \mu \mathrm{m}$ into the substrate, disrupting the $\gamma+\gamma^{\prime}$ substrate microstructure. Characterization of the oxide formed on a $\gamma+\gamma^{\prime}$ composition showed that even 30 at. $\%$ Pt did not prevent the formation of a Ni-rich spinel layer at $1200^{\circ} \mathrm{C}$. In order to assist the coating development process, model alloys also were evaluated. Other Pt group metals (Pd and Ir) were evaluated as well as the addition of $\mathrm{Cr}$ and various $\mathrm{Hf}$ levels. As expected, $\mathrm{Cr}$ and $\mathrm{Hf}$ were beneficial for oxidation resistance. However, Pd was not an adequate replacement for Pt because of the multi-phase microstructure that formed. A $\gamma+\gamma^{\prime}$ composition had a $1000^{\circ} \mathrm{C}$ yield stress in compression that was significantly higher than $\gamma^{\prime}-\mathrm{Ni}_{3} \mathrm{Al}$ or $\beta-\mathrm{NiAl}$. Also, the thermal expansion coefficient was very similar to other Ni-Al alumina-formers. The performance of $\gamma+\gamma^{\prime}$ compositions are very promising, however, sensitivity to superalloy substrate composition, Pt interdiffusion during long-term service, spinel formation and the potential need for a secondary processing step are areas of concern for this class of coatings.
\end{abstract}

\section{Introduction}

There has been significant recent interest in the use of two-phase, $\gamma$ (Ni-solid solution) and $\gamma^{\prime}\left(\mathrm{Ni}_{3} \mathrm{Al}\right)$ bond coatings (sometimes called Pt diffusion coatings or low-cost bond coats) for thermal barrier coatings (TBC's) on superalloys because of their combination of oxidation resistance, good mechanical properties, limited Al interdiffusion behavior and lower cost.[1-9] However, limited information is available about their fabrication, performance and limitations. The current study is being conducted to evaluate the potential of this class of coatings for next generation power generation applications where long-term durability and improved corrosion resistance are issues. The burning of synthetic gas from coal in turbines will increase the water vapor content in the combustion gas[10] and may bring higher levels of other impurities, such as sulfur, than current natural-gas fired turbines. Coatings based on $\gamma+\gamma^{\prime}$ compositions may be attractive for this application because they are reported to have lower Al interdiffusion[2], which may result in increased lifetime, and good hot corrosion resistance.[5]

Like aero-turbines, the current generation of land-based turbines relies on TBC's to protect hot section components. Lifetime of TBCs has been related to the adhesion of the alumina scale that forms at the interface between the metallic bond coating and the low thermal conductivity, ceramic (typically $\mathrm{Y}_{2} \mathrm{O}_{3}$-stabilized $\mathrm{ZrO}_{2}$ (YSZ)) top coat.[11-12] The scale is a weak link that must be almost ideally adherent to retain the top coat. Therefore, characterizing the formation, growth and adhesion of this oxide layer is an initial method for assessing the potential of this class of materials as bond coatings. Coatings on superalloy substrates and model coating alloys have been evaluated in furnace cycling tests in dry $\mathrm{O}_{2}$ and in air with $10-90$ vol. $\% \mathrm{H}_{2} \mathrm{O}$. Using model alloys allowed evaluation of possible modifications in coating composition for improved performance or due to compositional changes during service. Also, because oxidation resistance is not the only factor that governs coating performance, an initial assessment was made of the thermal expansion behavior and the high temperature yield strength of a $\gamma+\gamma^{\prime}$ alloy relative to other aluminide compositions. The current assessment is that $\gamma+\gamma^{\prime}$ coatings have some attractive features including oxidation resistance and mechanical properties. Concerns about $\mathrm{Pt}$ interdiffusion in the substrate, the formation of Ni-rich spinel oxide, sensitivity to superalloy composition and the need for secondary processing steps are discussed in this paper.

\section{Experimental Procedure}

The model alloys were vacuum induction melted at Oak Ridge National Laboratory (ORNL) using a water-chilled copper mold. Chemical compositions were measured by inductively-coupled plasma analysis and combustion analysis on as-cast material, Table I. All compositions in the paper are in atomic percent. After casting, alloys were annealed for $4 \mathrm{~h}$ at $1300^{\circ} \mathrm{C}$ in quartz ampules or at $10^{-4} \mathrm{~Pa}\left(10^{-6}\right.$ Torr) vacuum except for Ni-5Pt-9Cr-22Al which melted at $<1300^{\circ} \mathrm{C}$ and was annealed at $1200^{\circ} \mathrm{C}$. Oxidation coupons (1-1.5mm thick, typically $15 \mathrm{~mm}$ diameter) were polished to a $0.3 \mu \mathrm{m}$ alumina finish and cleaned in acetone and methanol prior to oxidation.

Two types of General Electric Aircraft Engines superalloy substrates were coated, directionally-solidified (DS) alloy 142 (PCC Airfoils) and single crystal (SX) alloy N5 (Howmet), TableI. The substrates were first grit-blasted (alumina) and then 


\begin{tabular}{|c|c|c|c|c|c|c|c|c|}
\hline & $\mathrm{Ni}$ & $\mathrm{Al}$ & Hf & $\mathrm{Pt}$ & $\mathrm{Cr}$ & $\mathrm{C}$ (ppma) & S (ppma) & Other \\
\hline $\mathrm{Ni}-48 \mathrm{Al}+\mathrm{Hf}$ & 51.6 & 48.3 & 0.056 & & $<0.01$ & 340 & $<4$ & \\
\hline $\mathrm{Ni}-51 \mathrm{Al}+\mathrm{Hf}$ & 48.8 & 51.1 & 0.050 & & $<0.01$ & 350 & $<4$ & \\
\hline $\mathrm{Ni}-42.5 \mathrm{Al}+\mathrm{Hf}$ & 58.0 & 41.9 & 0.048 & & $<0.01$ & 380 & $<4$ & \\
\hline $\mathrm{Ni}-25 \mathrm{Al}+\mathrm{Hf}$ & 75.1 & 24.8 & 0.057 & & $<0.01$ & 410 & $<4$ & \\
\hline $\mathrm{Ni}-22 \mathrm{Al}-0.05 \mathrm{Hf}$ & 76.9 & 22.8 & 0.049 & & 0.01 & 770 & $<4$ & \\
\hline $\mathrm{Ni}-22 \mathrm{Al}+0.5 \mathrm{Hf}$ & 77.5 & 21.9 & 0.493 & & $<0.01$ & 130 & $<10$ & \\
\hline $\mathrm{Ni}-22 \mathrm{Al}-5 \mathrm{Pt}$ & 73.0 & 22.0 & $<0.01$ & 4.9 & $<0.01$ & 150 & $<10$ & \\
\hline $\mathrm{Ni}-22 \mathrm{Al}-5 \mathrm{Pt}-0.02 \mathrm{Hf}$ & 72.8 & 22.1 & 0.016 & 5.0 & $<0.01$ & 240 & $<10$ & \\
\hline Ni-22Al-5Pt-0.4Hf & 72.8 & 21.8 & 0.403 & 4.9 & $<0.01$ & 130 & $<4$ & \\
\hline $\mathrm{Ni}-22 \mathrm{Al}-10 \mathrm{Pt}$ & 67.8 & 22.2 & $<0.01$ & 9.9 & $<0.01$ & 270 & $<10$ & \\
\hline $\mathrm{Ni}-22 \mathrm{Al}-10 \mathrm{Pt}-0.06 \mathrm{Hf}$ & 67.0 & 22.6 & 0.062 & 10.2 & 0.01 & 110 & $<10$ & \\
\hline $\mathrm{Ni}-22 \mathrm{Al}-10 \mathrm{Pt}-0.4 \mathrm{Hf}$ & 68.1 & 21.7 & 0.393 & 9.7 & 0.01 & 120 & $<4$ & \\
\hline $\mathrm{Ni}-22 \mathrm{Al}-15 \mathrm{Pt}-0.06 \mathrm{Hf}$ & 62.2 & 22.5 & 0.061 & 15.1 & 0.01 & 180 & $<10$ & \\
\hline $\mathrm{Ni}-22 \mathrm{Al}-30 \mathrm{Pt}-0.02 \mathrm{Hf}$ & 48.0 & 22.1 & 0.021 & 29.5 & 0.19 & 80 & $<10$ & \\
\hline Ni-22Al-5Pt-9Cr & 63.5 & 21.4 & 0.074 & 4.8 & 10.0 & 230 & $<4$ & $0.021 \mathrm{Y}$ \\
\hline Ni-22Al-10Pt-5Cr & 63.2 & 21.4 & 0.070 & 10.2 & 5.0 & 150 & $<4$ & $0.067 \mathrm{Y}$ \\
\hline $\mathrm{Ni}-22 \mathrm{Al}-5 \mathrm{Ir}+\mathrm{Hf}$ & 73.5 & 21.5 & 0.072 & & 0.01 & 160 & 11 & $4.9 \mathrm{Ir}$ \\
\hline Ni-22Al-10Pd & 66.1 & 23.9 & 0.078 & $<0.01$ & 0.01 & 230 & $<4$ & $9.8 \mathrm{Pd}$ \\
\hline $\mathrm{Ni}-22 \mathrm{Al}-20 \mathrm{Pd}$ & 57.7 & 22.4 & 0.079 & $<0.01$ & 0.01 & 200 & $<4$ & 19.7 Pd \\
\hline NiCrAlYHf & 61.4 & 18.9 & 0.046 & & 19.5 & 420 & 5 & $0.006 \mathrm{Y}$ \\
\hline MCrAlY & 40.4 & 23.5 & $<0.01$ & & 17.4 & 420 & 8 & 18.5 Co, 0.15 Y \\
\hline Alloy 142 & 59.5 & 13.9 & 0.520 & & 7.8 & 6000 & 11 & $\begin{array}{l}11.9 \mathrm{Co}, 2.1 \mathrm{Ta}, 1.5 \mathrm{~W} \\
0.9 \mathrm{Mo}, 0.9 \mathrm{Re}\end{array}$ \\
\hline Alloy N5 & 64.9 & 13.9 & 0.043 & & 7.8 & 3180 & 4 & 7.3Co,2.1Ta,1.6W \\
\hline & & & & & & & & $0.9 \mathrm{Mo}, 1 \mathrm{Re}, 0.011 \mathrm{Y}$ \\
\hline
\end{tabular}

electroplated with $\sim 7$ or $12 \mu \mathrm{m}$ of Pt in a laboratory scale bath at Tennessee Technological University (TTU). The coatings were then annealed for $2 \mathrm{~h}$ at $1100^{\circ}$ or $1175^{\circ} \mathrm{C}$ in a vacuum of $10^{-4} \mathrm{~Pa}$ (10-6 Torr).

Two types of cyclic oxidation experiments were conducted: (1) $500 \mathrm{~h}$ cycles in laboratory air at $1000^{\circ} \mathrm{C}$ in a box furnace with specimens in individual, pre-annealed alumina crucibles which captured any spalled oxide [13]; or (2) an automated test rig, where the specimens were hung by Pt-Rh wire and cycled for $1 \mathrm{~h}$ at $1100^{\circ}$ or $1150^{\circ} \mathrm{C}$ and $10 \mathrm{~min}$ cooling in dry, flowing $\mathrm{O}_{2}$ or in air with 10 90 vol. $\% \mathrm{H}_{2} \mathrm{O}$. For the wet air tests at $1100^{\circ} \mathrm{C}$, a controlled quantity of distilled water was atomized into the gas stream above its condensation temperature. Specimen mass change was measured using a Mettler-Toledo model AG245 balance.

After oxidation, specimen characterization included a field emission gun, scanning electron microscope (SEM) equipped with an energy dispersive $\mathrm{x}$-ray spectrometer (EDS); and electron probe microanalysis (EPMA) using wavelength dispersive $\mathrm{x}$-ray analysis. Specimens were $\mathrm{Cu}$-coated before being sectioned for metallography. A scanning transmission electron microscope (STEM) equipped with EDS was used to analyze cross-sectional specimens fabricated by focused ion beam (FIB) milling [14]. During FIB specimen preparation, a W layer was deposited to protect the gas interface of the scale.

\section{$\underline{\text { Coating Fabrication }}$}

\section{Results}

Because there are few details in the literature about the fabrication procedure for $\gamma+\gamma^{\prime}$ coatings, it is difficult to know if there is an optimal process or if a two stage process is needed. The second stage could be a pack or CVD process to increase the $\mathrm{Al}, \mathrm{Cr}, \mathrm{Hf}$, etc. content of the coating after Pt-plating [5,7,15,16]. The first $\gamma+\gamma^{\prime}$ coatings $[3,4,9,15]$ made at ORNL/TTUused $\sim 7 \mu \mathrm{m} \mathrm{Pt}$, the same amount as in conventional low activity chemical vapor deposition aluminide coatings[17], and a $2 \mathrm{~h}$ vacuum anneal at $1150^{\circ}$ or $1175^{\circ} \mathrm{C}$. However, these coatings generally showed inferior oxidation resistance to conventional Pt-modified aluminide coatings on the same substrates $[4,9,15]$.

Based on open literature and patent information,[7,18-20] two parameters were selected for evaluation: Pt thickness and annealing temperature[21]. Figure 1 shows the effect of $\mathrm{Pt}$ thickness on the coating $\mathrm{Pt}$ and $\mathrm{Al}$ contents. Obviously the $\mathrm{Pt}$ content was higher when $12 \mu \mathrm{m}$ of $\mathrm{Pt}$ was deposited. Due to $\mathrm{Pt}$ lowering the activity of $\mathrm{Al},[2,22]$ the coating became enriched in $\mathrm{Al}$ and slightly depleted the adjacent substrate in Al compared to the average N5 substrate content of $13.9 \%$ Al, Table I. Somewhat surprisingly, the Al content was slightly lower with the higher $\mathrm{Pt}$ content, Figure 1. However, the Ni content was lower in the coating with more Pt.

Varying the annealing temperature between $1100^{\circ}$ and $1175^{\circ} \mathrm{C}$ had a minor effect on the coating content.[21] The biggest difference was a higher $\mathrm{Al}$ content with the higher annealing temperature. In recent cyclic oxidation tests, the performance of coatings with $12 \mu \mathrm{m}$ Pt and a $2 \mathrm{~h} 1175^{\circ} \mathrm{C}$ anneal have been compared to coatings with a $7 \mu \mathrm{m}$ Pt layer.

\section{$\underline{\text { Cyclic Oxidation Performance of Coatings }}$}

Figures 2 and 3 show some of the cyclic oxidation mass gain results for the $\gamma+\gamma$ ' coatings with an initial Pt thickness of 7 or $12 \mu \mathrm{m}$.[21] In both cases, the mass change for a specimen of $\mathrm{NiAl}+\mathrm{Hf}$ is shown as a baseline, adherent alumina-former. At 


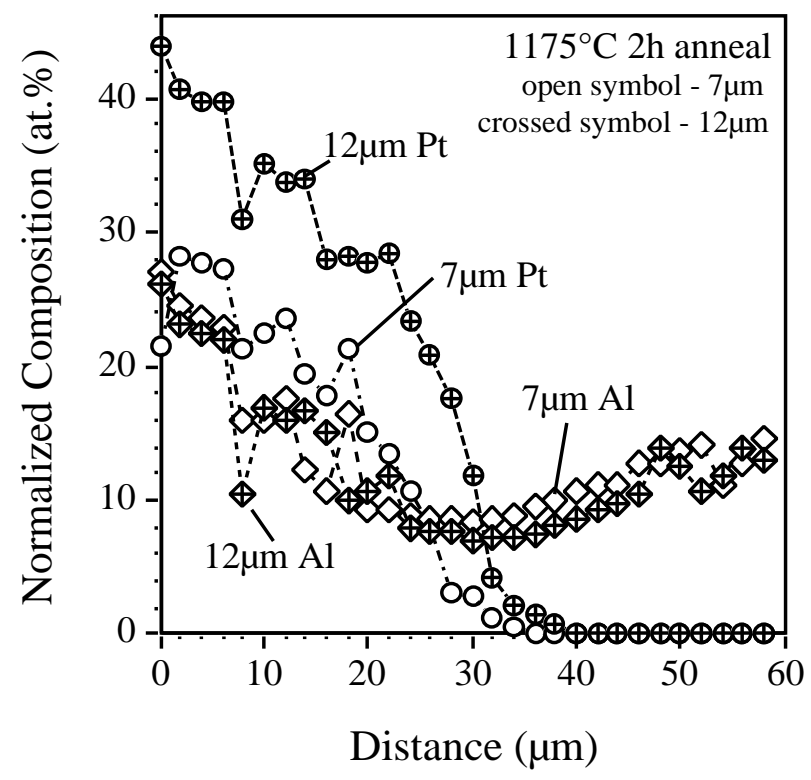

Figure 1. EPMA composition profiles from metallographically sectioned coatings with $\sim 7$ or $12 \mu \mathrm{m}$ of electroplated $\mathrm{Pt}$ on the surface of $\mathrm{N} 5+\mathrm{Y}$ after annealing for $2 \mathrm{~h}$ at $1175^{\circ} \mathrm{C}$.

$1100^{\circ} \mathrm{C}$, increasing the Pt content reduced the mass gain for $\gamma+\gamma^{\prime}$ coated alloy 142 . With only $7 \mu \mathrm{m}$ of $\mathrm{Pt}$, a significant amount of $\mathrm{Hf}$ internal oxidation occurred, Figure $4 \mathrm{a}$, for this DS alloy with $0.52 \mathrm{Hf}$, Table I. In model alloys, increasing the Pt content decreased the amount of Hf internal oxidation.[6,23] Therefore, the lower mass gain observed for the coating on 142 with the higher Pt content, Figure 2, was attributed to a reduction in $\mathrm{Hf}$ internal oxidation. This specimen has not yet been characterized to confirm this hypothesis. At $1150^{\circ} \mathrm{C}$, the $7 \mu \mathrm{m} \mathrm{Pt} \gamma+\gamma^{\prime}$ coating on alloy 142 performed very poorly with significant spallation in less

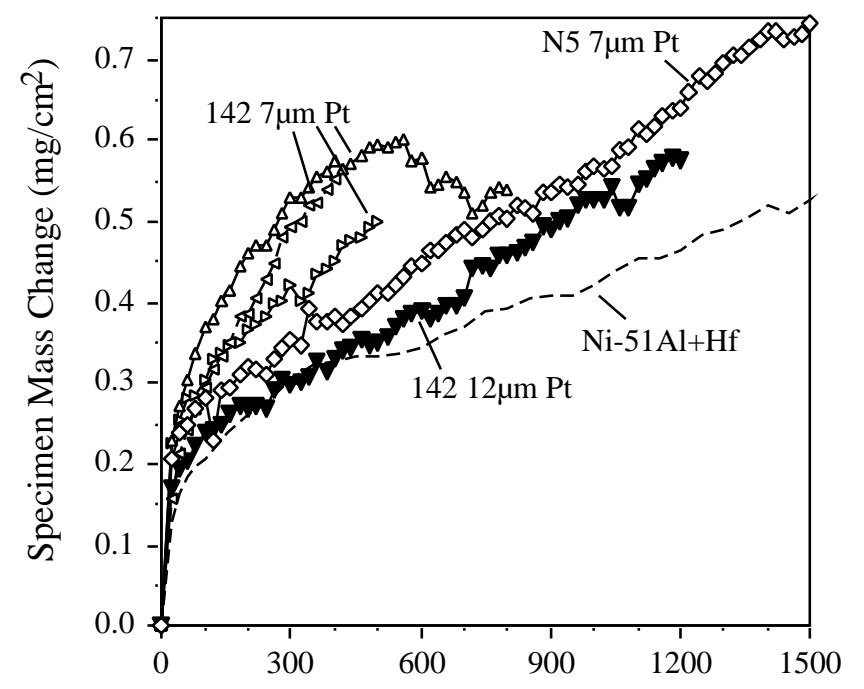

Number of $1 \mathrm{~h}$ Cycles at $1100^{\circ} \mathrm{C}$

Figure 2. Specimen mass changes for $\gamma+\gamma^{\prime}$ coatings on 142 and N5 substrates during $1 \mathrm{~h}$ cycles at $1100^{\circ} \mathrm{C}$ in dry $\mathrm{O}_{2}$.

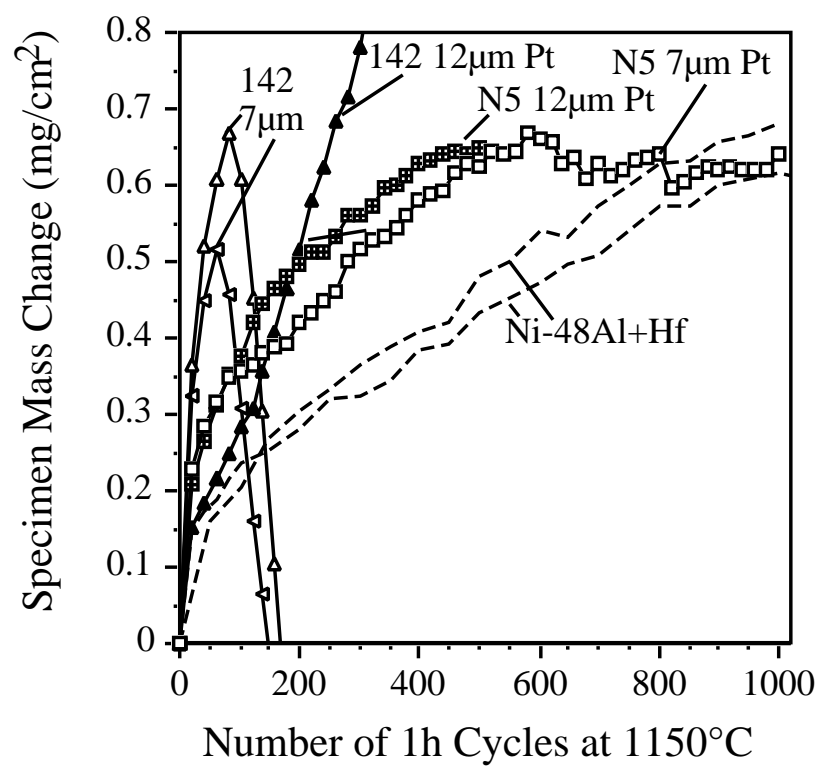

Figure 3. Specimen mass changes for $\gamma+\gamma^{\prime}$ coatings on 142 and N5 substrates during $1 \mathrm{~h}$ cycles at $1150^{\circ} \mathrm{C}$ in dry $\mathrm{O}_{2}$.

than 100 cycles on two different specimens, Figure 3. Increasing the Pt content decreased the initial mass gain, but the subsequent mass gain was higher than for coated N5 as Ni-rich oxide nodules began to form after 200 cycles. On a high Hf content DS superalloy such as alloy $142, \gamma+\gamma^{\prime}$ coatings may not be appropriate for such high temperature applications.

For N5 substrates with only $0.04 \mathrm{Hf}, \gamma+\gamma^{\prime}$ coatings with only a $7 \mu \mathrm{m}$ Pt layer have shown excellent cyclic oxidation resistance, with a relatively low mass gain at $1100^{\circ} \mathrm{C}$ and little indication of scale spallation after $>1,500$ cycles, Figure 2. (This particular N5 variation contains Y, Table I, the performance of other variations

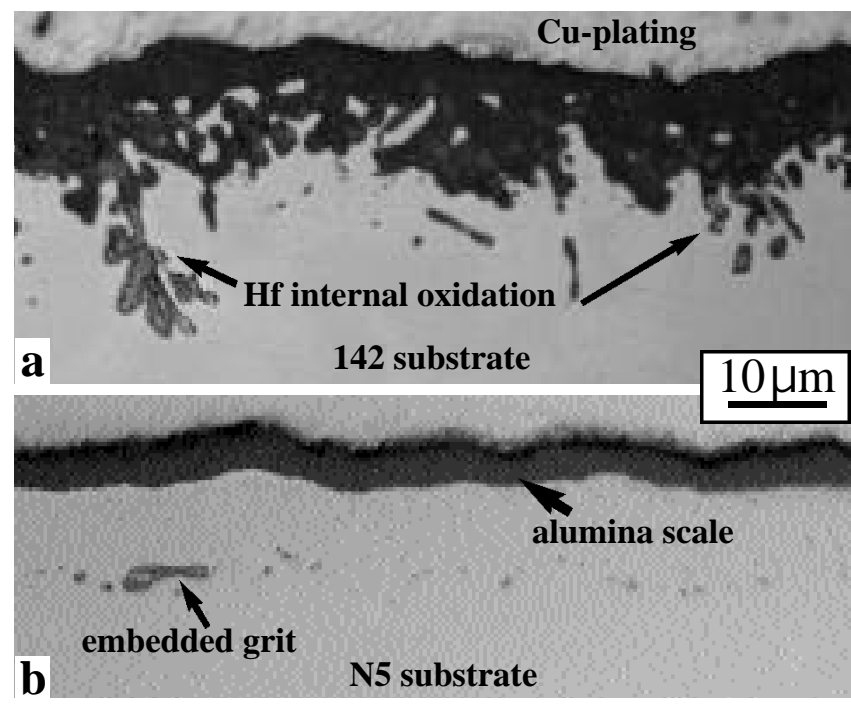

Figure 4. Light microscopy of metallographic sections of the scale formed on a $\gamma+\gamma^{\prime}(7 \mu \mathrm{m} \mathrm{Pt})$ coating (a) on alloy 142 after $800,1 \mathrm{~h}$ cycles at $1100^{\circ} \mathrm{C}$ and (b) on alloy $\mathrm{N} 5$ after 1,000 1-h cycles at $1150^{\circ} \mathrm{C}$. 
without $\mathrm{Y}$ are reported elsewhere.[9,21]) At $1150^{\circ} \mathrm{C}$, the $\gamma+\gamma^{\prime}$ coating on N5 with $12 \mu \mathrm{m}$ Pt did not show any signs of spallation after 400 cycles, Figure 3 . However, with a $7 \mu \mathrm{m}$ Pt coating, small amounts of scale spallation were observed after $\sim 600$ cycles, corresponding to the small mass losses, Figure 3. Similar scale spallation was not observed for conventional Pt-modified aluminide coatings on this substrate at this temperature.[9] After 1,000 cycles, the $7 \mu \mathrm{m}$ N5 coating specimen was sectioned and characterized. Figure $4 \mathrm{~b}$ shows the $\sim 5 \mu \mathrm{m}$ alumina scale formed on the coated substrate with virtually no internal oxidation. The second phase precipitates forming a line in the coating contained $\mathrm{Al}$ and $\mathrm{O}$ and are likely remnants from the grit blasting. Figure 5 is an SEM image of the same coating to show the $\gamma+\gamma^{\prime}$ microstructure. There appears to be a $\gamma$ layer adjacent to the surface oxide followed by an almost a complete layer of $\gamma^{\prime}$. Underneath the coating, an extensive $\gamma^{\prime}$ depletion zone is shown in the N5 substrate. An EPMA line profile in Figure 6 shows the concentration of $\mathrm{Pt}$ and $\mathrm{Al}$ to a depth of $240 \mu \mathrm{m}$ where the $\mathrm{Pt}$ content had dropped to $<0.5 \%$ after the $1,000 \mathrm{~h}$ exposure at $1150^{\circ} \mathrm{C}$. Compared to the original coating composition, also shown in Figure 6, a significant amount of $\mathrm{Pt}$ and $\mathrm{Al}$ interdiffusion had occurred. The $\sim 5 \mu \mathrm{m}$ surface $\gamma$ layer contained only $\sim 5 \% \mathrm{Pt}$ and $<11 \% \mathrm{Al}$. The underlying $\gamma^{\prime}$ layer with $\sim 19 \% \mathrm{Al}$ and $7 \% \mathrm{Pt}$ was significantly thicker than the original coating. Due to $\mathrm{Al}$ interdiffusion and $\mathrm{Al}$ consumption via oxidation (and spallation), a significant drop in the adjacent substrate Al content had occurred, Figure 6 , to at least $200 \mu \mathrm{m}$. Characterization of the $12 \mu \mathrm{m} \mathrm{Pt}$ coating after 1,000 cycles is needed to determine if a higher $\mathrm{Pt}$ content affects this interdiffusion behavior.

\section{Effect of $\mathrm{H}_{2} \underline{\mathrm{O} \text { on Oxidation Behavior }}$}

Because of the higher water vapor contents in the combustion environment with the use of coal-derived synthetic gas, the oxidation performance of $\gamma+\gamma^{\prime}$ coatings also was investigated in higher water vapor contents than the typical $10-15 \% \mathrm{H}_{2} \mathrm{O}$ found with burning natural gas.[10,24] Figure 7 a shows the mass gain behavior of $7 \mu \mathrm{m} \mathrm{Pt} \gamma+\gamma^{\prime}$ coatings on N5 substrates at 0,50 and $90 \mathrm{vol} . \% \mathrm{H}_{2} \mathrm{O}$. The mass change was very similar to the baseline

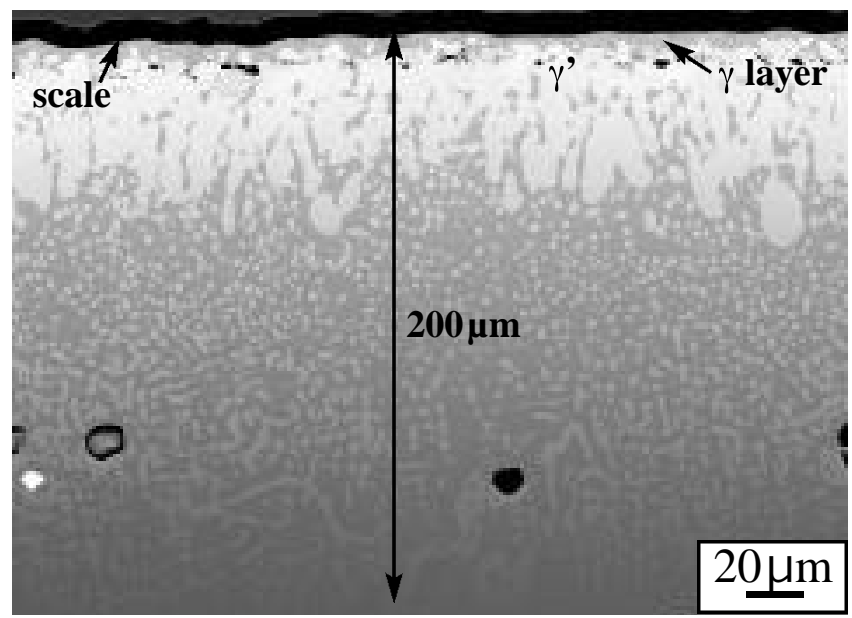

Figure 5. SEM secondary electron image of a polished section of the $7 \mu \mathrm{m}$ Pt coating on $\mathrm{N} 5$ after oxidation at $1150^{\circ} \mathrm{C}$ for $1,000,1-$ $\mathrm{h}$ cycles in dry $\mathrm{O}_{2}$. The $\gamma^{\prime}$ layer is rich in $\mathrm{Pt}$ and appears lighter.

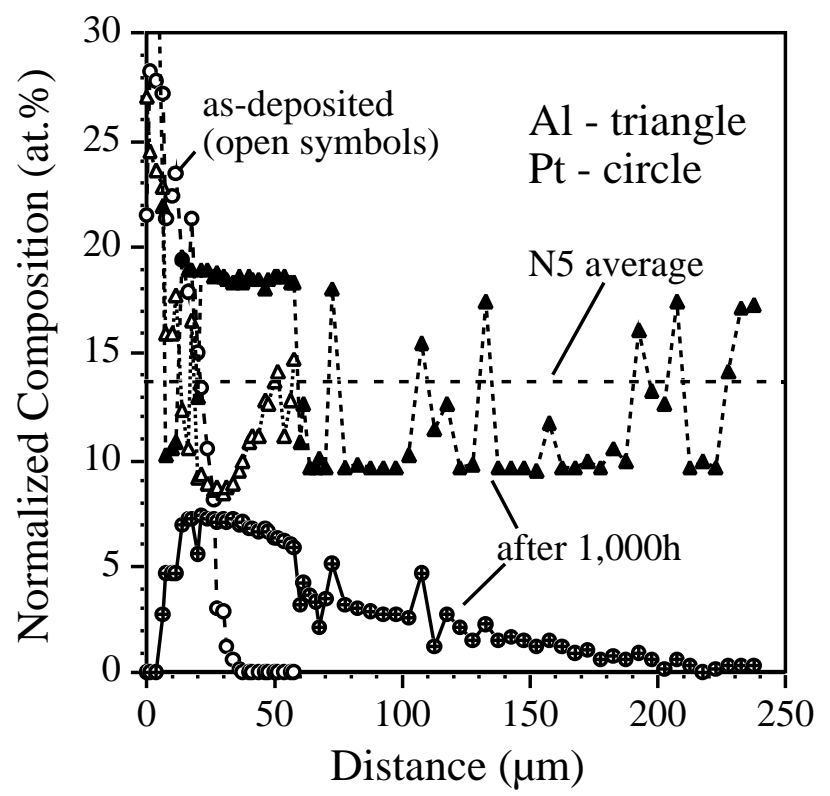

Figure 6. EPMA composition profiles from metallographically sectioned coatings with $\sim 7 \mu \mathrm{m}$ of electroplated Pt on the surface of $\mathrm{N} 5$ as-annealed and after 1,0001 -h cycles at $1150^{\circ} \mathrm{C}$. The dashed line shows the average Al content for the N5 substrate.

$\mathrm{NiAl}+\mathrm{Hf}$ that forms an adherent alumina scale (dashed line in Figure 7a). Figure $7 \mathrm{~b}$ shows the mass change for $7 \mu \mathrm{m} \mathrm{Pt} \gamma+\gamma^{\prime}$ coatings on 142 substrates. These specimens were stopped prior to 1000 cycles because of excessive scale spallation and coating degradation. Figure 8a shows scale spallation after exposure for only 300,1 -h cycles in $50 \% \mathrm{H}_{2} \mathrm{O}$. These results are consistent with prior studies of water vapor effects.[25-28] Substrates such as coated N5 that form adherent $\alpha-\mathrm{Al}_{2} \mathrm{O}_{3}$ scales tend to be less affected by water vapor than those that form less adherent scales, such as on 142 .

Besides the spallation for the coated 142 specimens, which may be due to the lower than optimal Pt $(7 \mu \mathrm{m})$ content, the other concern about these results is the increased mass gain with the addition of water vapor, Figure $7 \mathrm{~b}$. A similar increase was noted for a model Ni-22Al-10Pt-0.4Hf alloy which has a high Hf content like the 142 substrate, Table I. The increase in mass gain was attributed to increased formation of $\mathrm{Ni}$-rich, spinel type oxide, such as $\mathrm{NiAl}_{2} \mathrm{O}_{4}$. Figure $8 \mathrm{~b}$ shows the scale formed on coated 142 after 200, 1-h cycles in air $+90 \% \mathrm{H}_{2} \mathrm{O}$. The triangular features (arrows) are the hallmark of a cubic Ni-rich oxide, like $\mathrm{NiAl}_{2} \mathrm{O}_{4}$. Increased transient oxide formation also has been reported in previous studies of the role of water vapor.[27-28]

To put these $\gamma+\gamma$ ' coating results into perspective, Figure 9 shows the mass gain of two model bond coating alloys as a function of water vapor content during cyclic oxidation at $1100^{\circ} \mathrm{C}$. For Ni$48 \mathrm{Al}+\mathrm{Hf}$, the addition of water vapor caused a small increase in the mass gain with increasing water vapor content. The gas interface of the $\alpha-\mathrm{Al}_{2} \mathrm{O}_{3}$ scale showed signs of evaporation under these conditions.[24] This is consistent with a low level of reaction to form a volatile Al-OH type compound at this temperature.[29] 

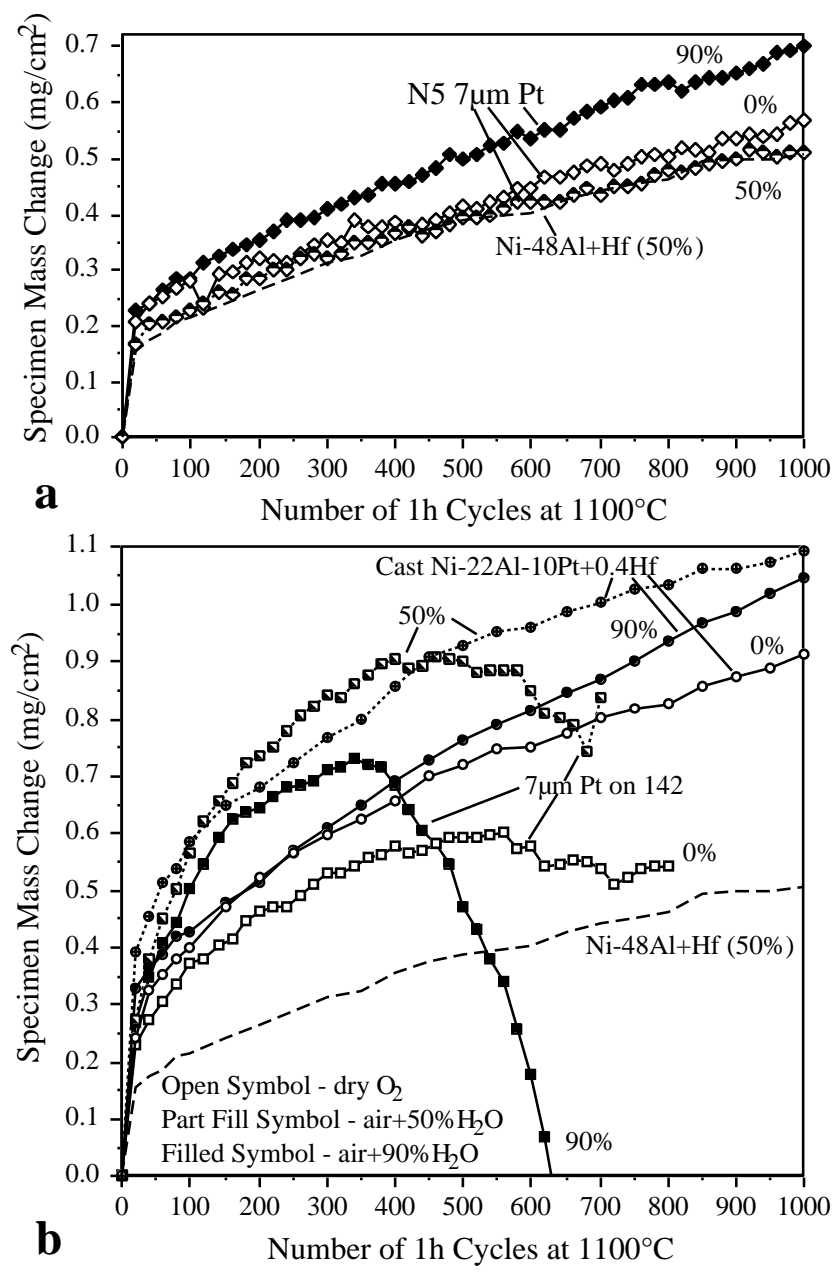

Figure 7. Specimen mass gain during $1 \mathrm{~h}$ cycles at $1100^{\circ} \mathrm{C}$ in dry $\mathrm{O}_{2}$ and air with 50 and $90 \mathrm{vol} \% \mathrm{H}_{2} \mathrm{O}$ for (a) coatings on $\mathrm{N} 5$ and (b) coatings on 142 and cast Ni-22Al-10Pt-0.4Hf.

For cast NiCrAlYHf, representative of MCrAlY-type coatings, the effect of water vapor was to slightly increase the scale spallation with the higher water vapor contents. The scale spallation for
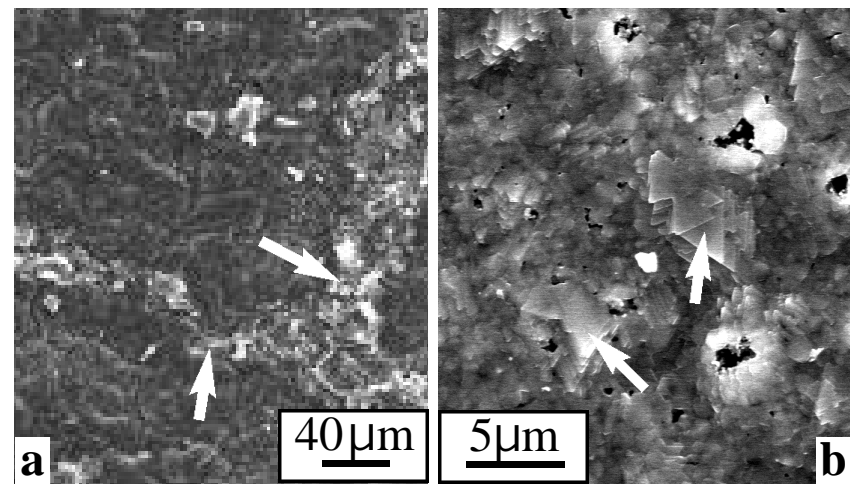

Figure 8. SEM secondary electron plan-view images of the scale formed on $7 \mu \mathrm{m} \mathrm{Pt}$ coating on 142 after oxidation at $1100^{\circ} \mathrm{C}$ for (a) $300,1-\mathrm{h}$ cycles in air $+50 \% \mathrm{H}_{2} \mathrm{O}$ and (b) 200, 1-h cycles in air $+90 \% \mathrm{H}_{2} \mathrm{O}$. Arrows in (a) point to spall, in (b) to faceted grains.

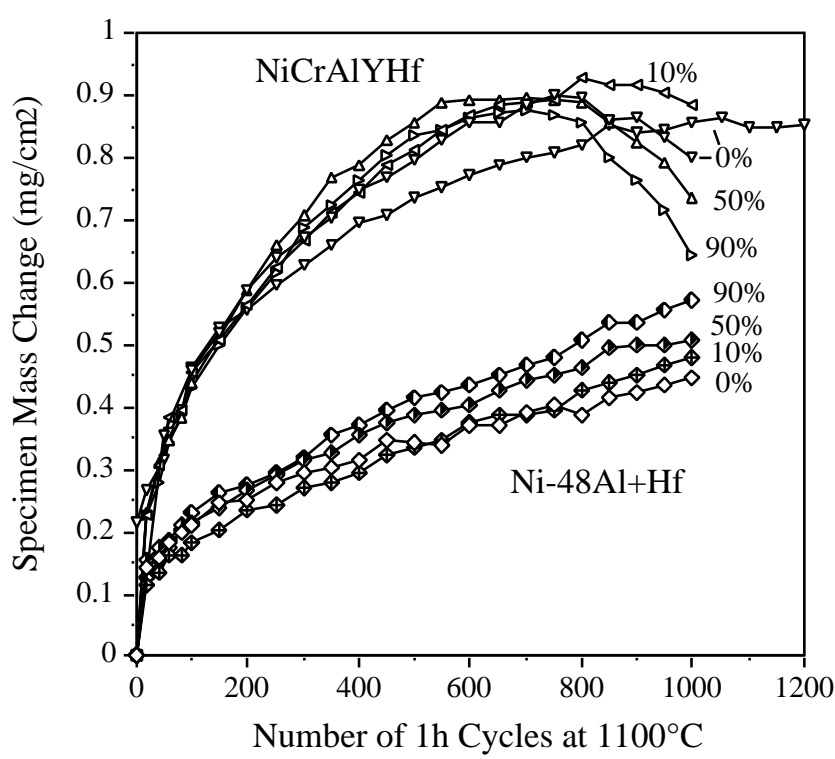

Figure 9. Specimen mass gain for cast $\mathrm{Ni}-20 \mathrm{Cr}-10 \mathrm{Al}+\mathrm{Y}, \mathrm{Hf}$ and $\mathrm{Ni}-48 \mathrm{Al}-0.05 \mathrm{Hf}$ specimens exposed to $1 \mathrm{~h}$ cycles at $1100^{\circ} \mathrm{C}$ in dry $\mathrm{O}_{2}$ or air with various vol. $\%$ of $\mathrm{H}_{2} \mathrm{O}$ from $10-90 \%$.

NiCrAlYHf is attributed to the faster scale growth (higher mass gain) compared to $\mathrm{NiAl}+\mathrm{Hf}$ and the higher coefficient of thermal expansion (CTE)[30], which increases the thermal stresses between the metal and alumina scale (see data in Fig. 18).

\section{$\underline{\text { Model } \gamma+\gamma^{\prime} \text { Alloy Oxidation Behavior }}$}

As with the model NiCrAlYHf and $\mathrm{NiAl}+\mathrm{Hf}$ alloys, model alloys also have been used to study the oxidation behavior in the $\gamma+\gamma$, system.[2,3,5-7] Because of the transient oxide formation and the interdiffusion observed in $\gamma+\gamma^{\prime}$ coatings, the primary interest for this study[23] was on the oxidation behavior of $\gamma+\gamma^{\prime}$ alloys with relatively low Pt contents, e.g. 5-10\%, that would help to understand the behavior of mature coatings. Also, to study the transient behavior of these materials, the temperature was reduced to $1000^{\circ} \mathrm{C}$, closer to actual coating application temperatures, especially in land-based turbines. (Higher temperature testing, i.e. $1100^{\circ}-1200^{\circ} \mathrm{C}$, should favor the formation of $\alpha-\mathrm{Al}_{2} \mathrm{O}_{3}$ because of the faster $\mathrm{Al}$ diffusion in the substrate and avoid the possible formation of metastable cubic alumina phases such as $\theta$ $\left.\mathrm{Al}_{2} \mathrm{O}_{3} \cdot[31,32]\right) \quad$ Figure 10 shows the effect of platinum group metal (PGM) additions (Pt, Pd, Ir) and $\mathrm{Hf}$ on the mass gain after $500 \mathrm{~h}$ at $1000^{\circ} \mathrm{C}$ in air. As a (dashed) baseline, $\mathrm{Ni}-48 \mathrm{Al}+0.05 \mathrm{Hf}$ sets a minimum in terms of no Ni-rich oxide formation, minimal Hf internal oxidation and slow alumina growth. The Ni-22Al alloys with no PGM addition showed higher mass gains, primarily due to the transient formation of Ni-rich oxides. (With 4000ppm $\mathrm{Hf}$, internal oxidation of $\mathrm{Hf}$ also added to the mass gain.) With modest (200-700ppm) Hf additions, increasing Pt additions reduced the amount of transient oxide and thus the mass gain decreased. For example, Figure 11a shows the thick Ni-rich oxide formed with only 5Pt. Alloys with no Hf or 4000ppm Hf showed a similar trend. However, there was an unusual change with increasing Pt content with 4000ppm Hf. With 5Pt, the mass gain 


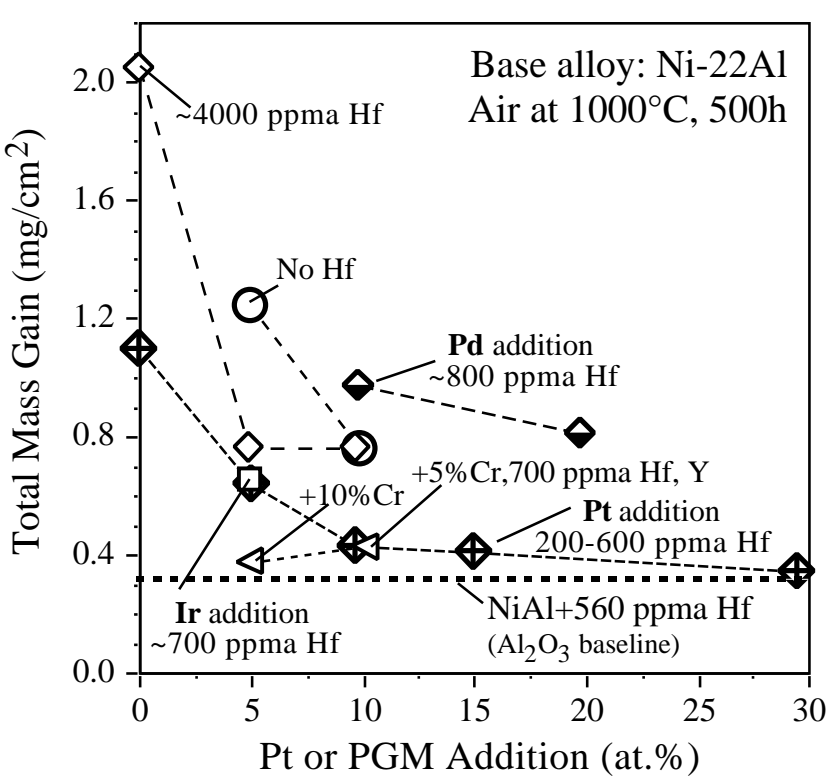

Figure 10. Total mass gain (specimen + spalled oxide) after a $500 \mathrm{~h}$ isothermal exposure at $1000^{\circ} \mathrm{C}$ in laboratory air for various precious metal and $\mathrm{Hf}$ additions (all in ppm) to alloys with 22at.\%Al.

was a combination of internal Hf oxidation, Fig. 11b, and Ni-rich oxide, indicated by the faceted gas interface in Fig. 12a. With $10 \% \mathrm{Pt}$ and high $\mathrm{Hf}$, the mass change was similar but the internal oxidation was eliminated, Fig. $11 \mathrm{c}$, due to the proposed interaction between Pt and Hf.[6,7] However, the gas interface was irregular due to the faster growth of $\theta-\mathrm{Al}_{2} \mathrm{O}_{3}$ with its hallmark[31,32] bladelike morphology, Fig. 12b. The metal-oxide interface, Figure 11c, also was irregular because the $\theta$ - to $\alpha-\mathrm{Al}_{2} \mathrm{O}_{3}$ phase transformation occurs non-uniformly.[32] Thus, these variations in composition resulted in complex changes in the oxidation behavior.

The issue of replacing Pt with another PGM also was explored. Both Pt and Ir showed a similar benefit at the 5\% level, Figure 10. Higher levels of $\mathrm{Pd}$, which is significantly less expensive than $\mathrm{Pt}$, were less effective due the formation of additional alloy phases, Figure 13. Higher Pd levels also resulted in a lower melting (solidus) temperature, $<1300^{\circ} \mathrm{C}$.[3] The co-addition of $5 \% \mathrm{Cr}$ and $\sim 10 \% \mathrm{Pt}$ did not decrease the mass gain but, the addition of both $\sim 700 \mathrm{ppm} \mathrm{Y}$ and 700ppm Hf resulted in additional internal oxidation, Figure 11d, that increased the mass gain in this specimen, Figure 10. A Ni-22Al-10Cr-5Pt specimen showed a lower mass gain but also a lower solidus temperature, $<1300^{\circ} \mathrm{C}$. Also, these levels of $\mathrm{Al}$ and $\mathrm{Cr}$ are almost high enough to eliminate transient oxide formation without a PGM addition.[33] In addition to improving the selective oxidation of $\mathrm{Al},[34]$ another reason for adding $\mathrm{Cr}$ was to increase the hot corrosion resistance.[5] In general, these results suggest that $>10 \% \mathrm{Pt}$ is needed to prevent significant Ni-rich oxide scale formation.

The formation of transient, Ni-rich oxides was further studied because these oxides are linked to TBC failure[35,36] and the $\mathrm{Al}_{2} \mathrm{O}_{3}-\mathrm{NiAl}_{2} \mathrm{O}_{4}$ interface is thought to be weak because of observations of interfacial voids.[37,38] However, because of the
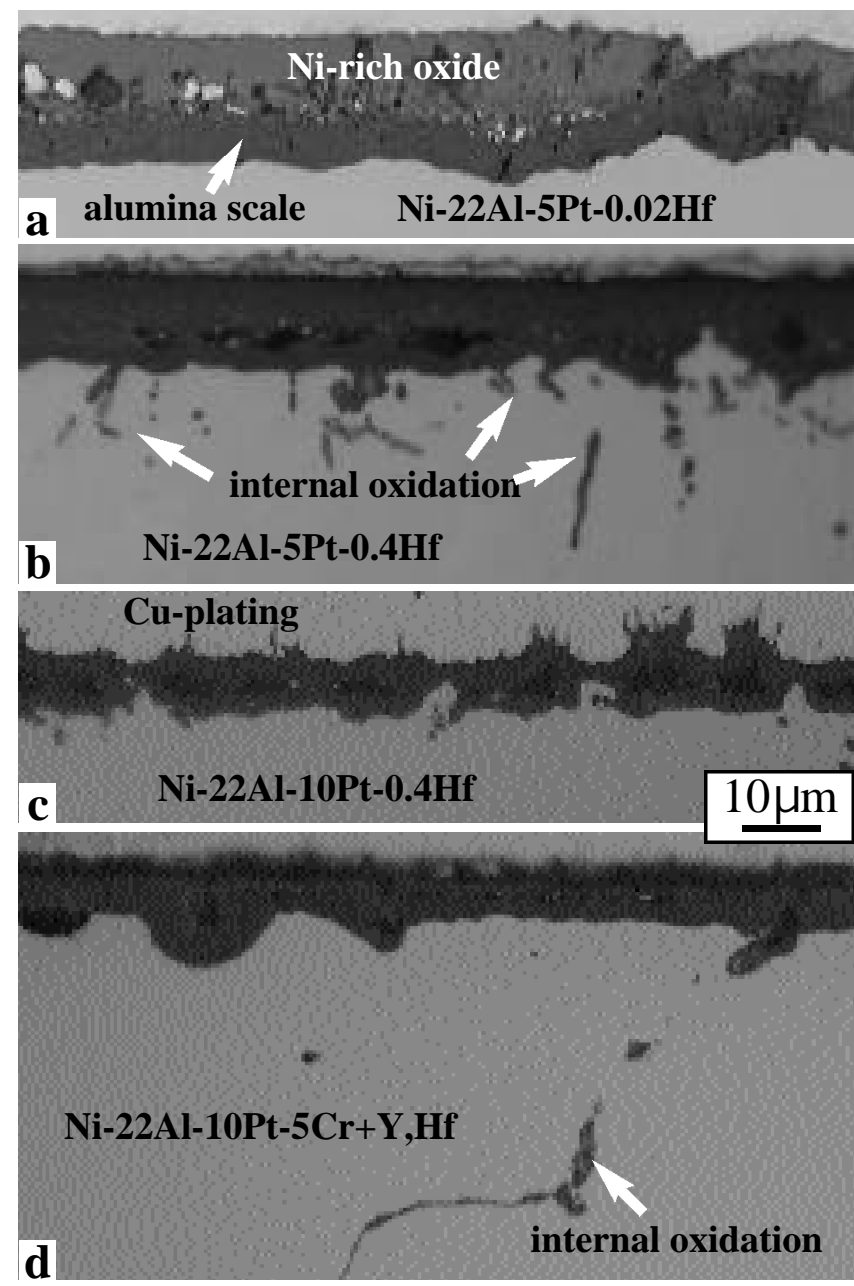

Figure 11. Light microscopy of $\mathrm{Cu}$-plated metallographic sections showing the alumina scale formed after $10,500 \mathrm{~h}$ cycles at $1000^{\circ} \mathrm{C}$ on (a) Ni-22Al-5Pt-0.02Hf, (b) Ni-22Al-5Pt-0.4Pt, (c) Ni-22Al10Pt-0.4Pt and (d) Ni-22Al-10Pt-5Cr-0.07Y,Hf.

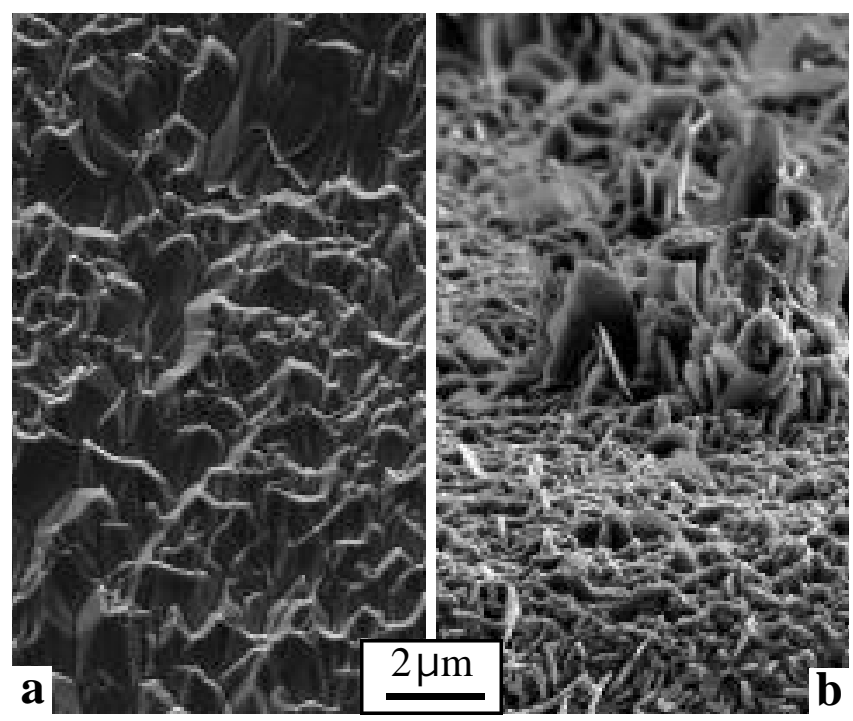

Figure 12. SEM secondary electron images of the scale formed after 10,500 -h cycles at $1000^{\circ} \mathrm{C}$ in laboratory air on (a) Ni-22Al5Pt-0.4Hf and (b) Ni-22Al-10Pt-0.4Hf. (b) is tilted. 


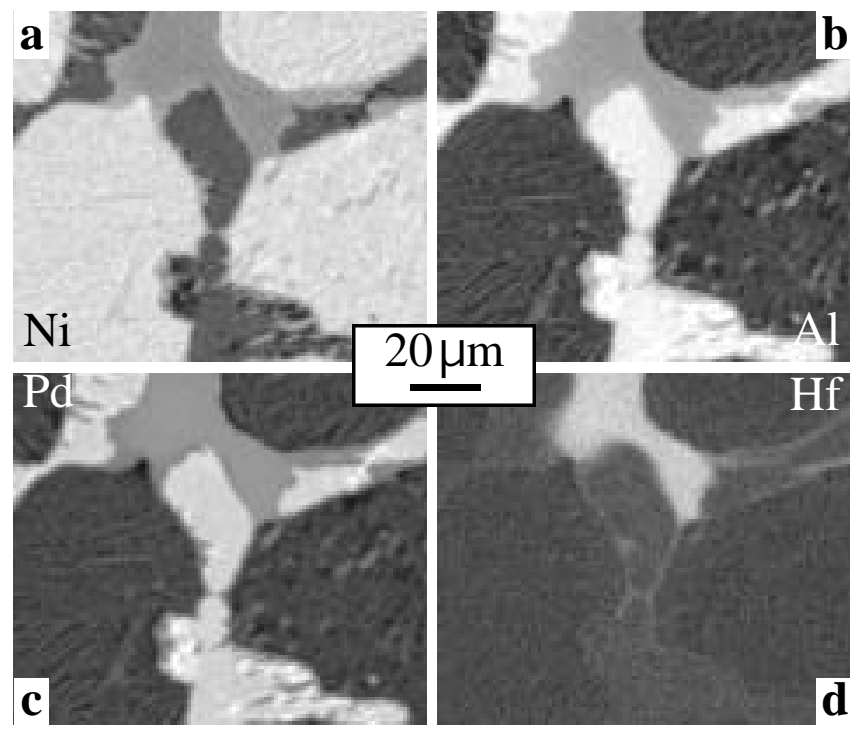

Figure 13. EPMA x-ray maps of the Ni-22Al-20Pd-0.07Hf alloy (a) Ni, (b) Al, (c) Pd and (d) Hf.

thin oxide layers formed on these alloys, characterization by SEM, EPMAor x-ray diffraction was difficult. The surface morphology was a good indicator, such as in Figure 12. Figure 14a shows the typical $\alpha-\mathrm{Al}_{2} \mathrm{O}_{3}$ morphology on $\beta-\mathrm{NiAl}+\mathrm{Hf}$ after oxidation at $1200^{\circ} \mathrm{C}$ for $2 \mathrm{~h}$. However, even with $30 \mathrm{Pt}, \gamma+\gamma^{\prime}$ compositions without $\mathrm{Cr}$ tended to show different surface morphologies, Figure 14b. To confirm the presence of a Ni-rich surface oxide, a TEM cross-section was made. Figure 15 shows the scale formed on $\mathrm{Ni}$ $22 \mathrm{Al}-30 \mathrm{Pt}-0.02 \mathrm{Hf}$ after $2 \mathrm{~h}$ at $1200^{\circ} \mathrm{C}$. As in Figure $11 \mathrm{c}$, the metaloxide interface is irregular, likely due to local variations in the phase transformation to the slower-growing $\alpha-\mathrm{Al}_{2} \mathrm{O}_{3}$ phase. Above the $\alpha-\mathrm{Al}_{2} \mathrm{O}_{3}$ layer is a distinct $\mathrm{NiAl}_{2} \mathrm{O}_{4}$ oxide layer. In this case, the $\mathrm{Al}_{2} \mathrm{O}_{3}-\mathrm{NiAl}_{2} \mathrm{O}_{4}$ interface appeared to be void free, similar to the observation for Ni-35Al+Hf.[3] Because of the underlying

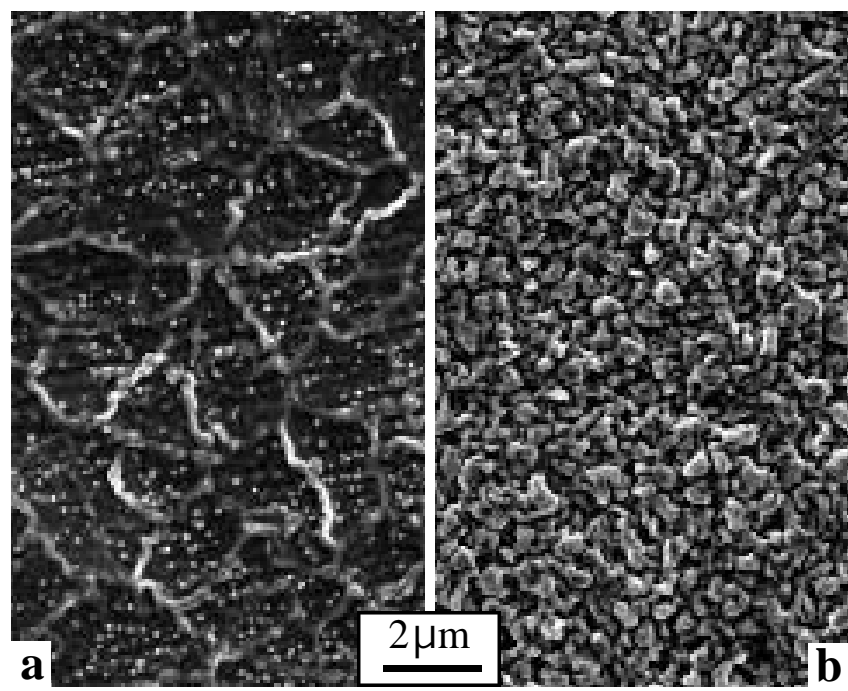

Figure 14. SEMsecondary electron plan-view images of the scale formed after $2 \mathrm{~h}$ at $1200^{\circ} \mathrm{C}$ in dry $\mathrm{O}_{2}$ on (a) Ni-42Al-0.05Hf and (b) Ni-30Pt-22Al-0.02Hf.

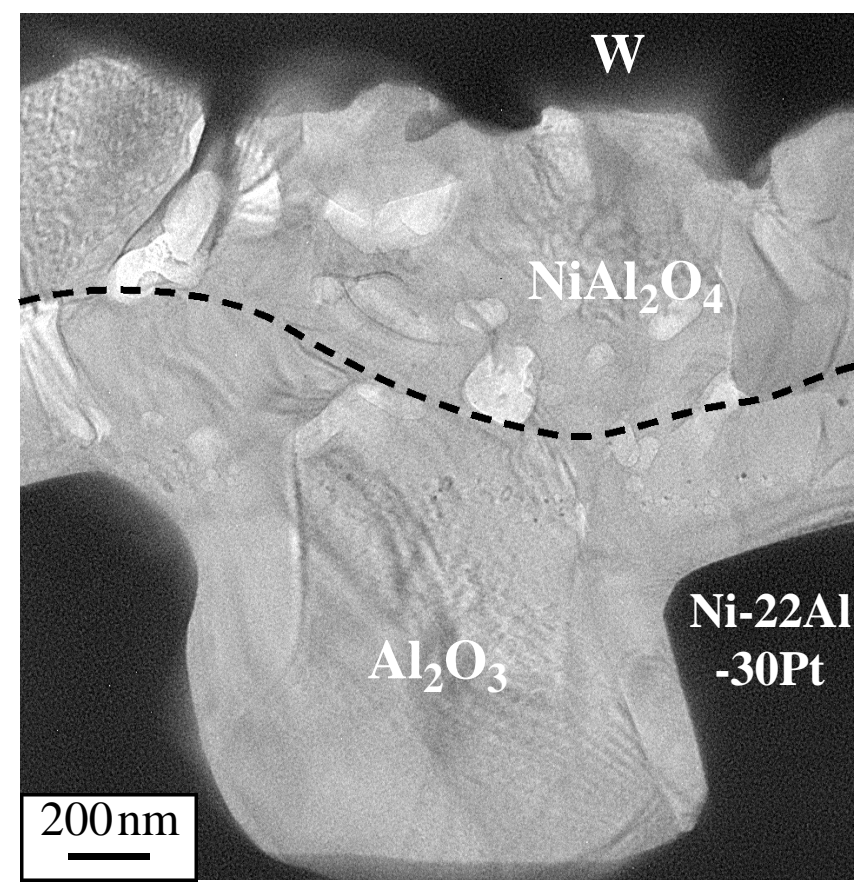

Figure 15. Bright field TEM cross-section image of the scale formed on $\mathrm{Ni}-22 \mathrm{Al}-30 \mathrm{Pt}-0.02 \mathrm{Hf}$ after $2 \mathrm{~h}$ at $1200^{\circ} \mathrm{C}$. The boundary between the outer spinel layer and the inner alumina layer is marked by a dashed line.

alumina layer, the $\mathrm{NiAl}_{2} \mathrm{O}_{4}$ likely would not grow further but could inhibit the bonding between the alumina scale and the ceramic top coat in a TBC system.

\section{$\underline{\text { Mechanical and Physical Property Measurements }}$}

Finally, the high temperature yield stress and CTEwere measured to obtain some additional information relevant to $\gamma+\gamma^{\prime}$ coatings. One of the reported [8] attractive features of $\gamma+\gamma^{\prime}$ coatings is good mechanical properties, yet no information has been provided in the open literature. As a first assessment of the high-temperature mechanical properties, compression yield tests were conducted on several $\mathrm{Ni}-\mathrm{Al}$ alloys at $1000^{\circ} \mathrm{C}$ with a $10^{-3} \mathrm{~s}^{-1}$ strain rate. (Additional details of the experimental procedure are available elsewhere.[39]) Figure 16 compares the $0.2 \%$ engineering yield stress of N5, Ni-22Al-10Pt-0.05Hf, Ni-25Al+0.05Hf, Ni-48Al+Hf and NiCoCrAlY, Table I. The yield stress of the $\gamma+\gamma^{\prime}$ composition was similar to N5 and significantly higher than NiAl or MCrAlY.

Figure 17 shows the mean CTEfor Ni-22Al-5Pt-0.02Hf as a function of temperature compared to other Ni-base materials.[23,30] (Experimental details are available elsewhere.[30]) The CTE was remarkably similar to $\beta-\mathrm{NiAl}$ at $1000^{\circ}-1200^{\circ} \mathrm{C}$ and showed no indications of a phase transformation, as in NiCoCrAlYor Ni-35Al.

\section{Discussion}

Because of the proprietary nature of bond coating development, particularly for these new $\gamma+\gamma^{\prime}$ coatings, there is little information 


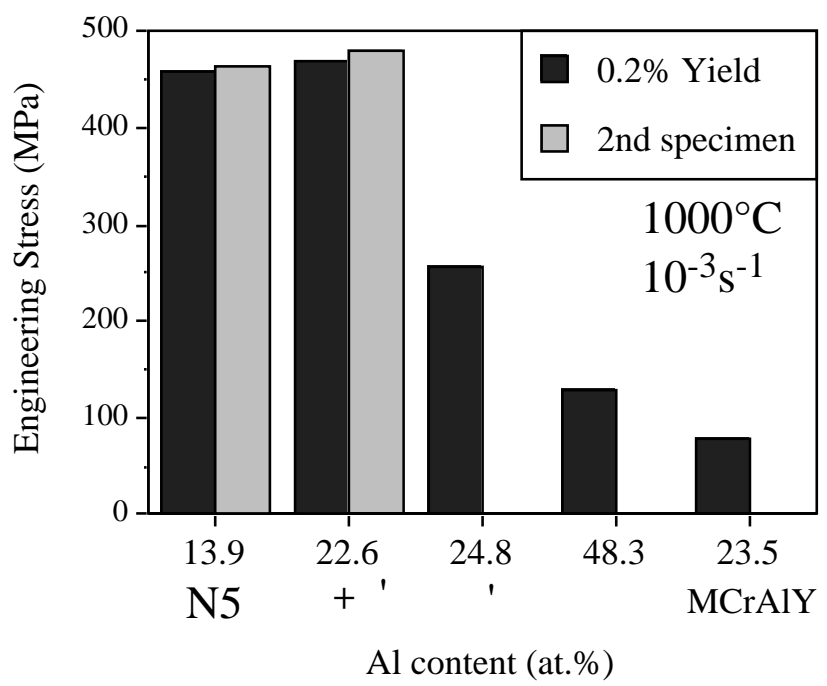

Figure 16. Compression yield stress $(0.2 \%)$ for various $\mathrm{Ni}-\mathrm{Al}$ phases with $\sim 500$ ppma $\mathrm{Hf}$ at $1000^{\circ} \mathrm{C}$. The Ni-22Al alloy also contained $10 \% \mathrm{Pt}$. For comparison, values for alloy N5

available in the literature on which to base an assessment. Therefore, an experimental program on coatings and model alloys has been conducted. The absence of coating fabrication details places the coating work at a particular disadvantage because of the many process variables, particularly for a secondary treatment. However, if $\gamma+\gamma$ ' coatings are to be "low cost" bond coatings (LCBC), the simple processing route reported here is necessary. In that case, two of the main variables are Pt thickness and annealing temperature and those are currently being assessed.[21]

For the model alloy work, the effects of Pt, Al and Hf observed here appeared to be consistent with the literature.[2,3,5-7,22,4044] One exception was the transient $\theta-\mathrm{Al}_{2} \mathrm{O}_{3}$ formation observed

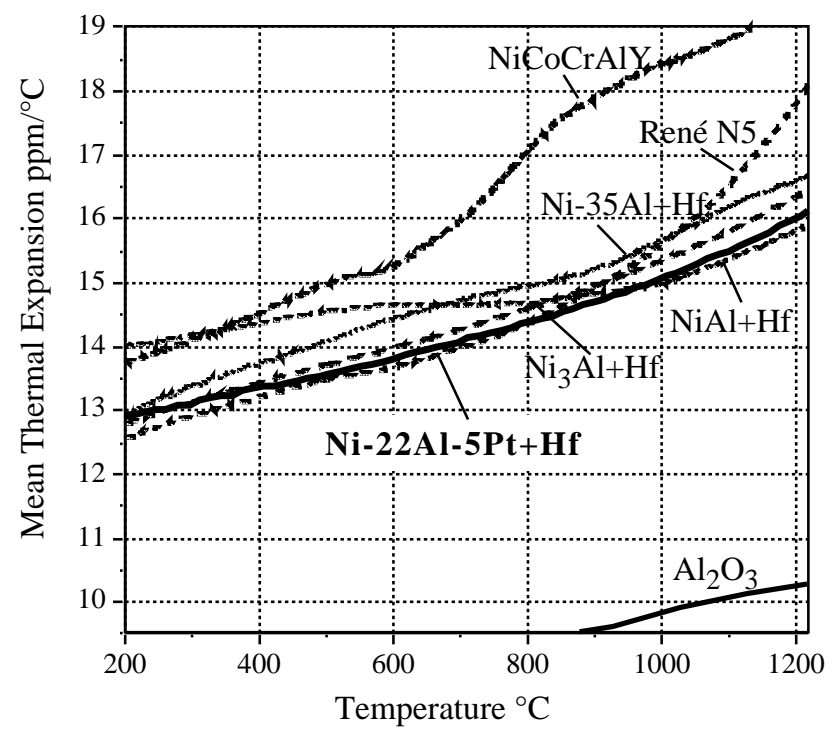

Figure 17. Mean coefficient of thermal expansion for Ni-22Al5Pt-0.02Hf (solid line) compared to other alloys and $\alpha-\mathrm{Al}_{2} \mathrm{O}_{3}$. at $1000^{\circ} \mathrm{C}$ on $\mathrm{Ni}-22 \mathrm{Al}-10 \mathrm{Pt}-0.4 \mathrm{Pt}$ which had not been discussed previously. The model alloy work on Pd and Ir did not appear to be a promising route for coating development. However, another study[44] suggested that a mixture of Pt and Ir was beneficial in $\gamma+\gamma^{\prime}$ alloys. Prior work on $\beta$ alloys indicated that Ir was more effective in improving scale adhesion than Pt.[42]

In general, the current work suggests that there are some very attractive features for $\gamma+\gamma$ coatings that should be further investigated. The hot corrosion resistance appears to be superior to conventional aluminides.[5] The oxidation resistance, particularly with the addition of Hf, appears to be superior to conventional Pt-modified and MCrAlY coatings. One advantage of the $\gamma+\gamma^{\prime}$ compositions is higher Hf solubility, which increases the processing window for $\mathrm{Hf}$ doping.[2] Prior efforts to dope conventional aluminide coatings with reactive elements such as Hf [45] have not been commercially successful. The optimal Hf content in $\gamma+\gamma^{\prime}$ coatings appears to be a function of the $\mathrm{Pt}$ content.[6] For example, Figures $11 \mathrm{~b}$ and $11 \mathrm{c}$ show the suppression of $\mathrm{Hf}$ internal oxidation by increasing the Pt content. This is an issue for the substrate Hf content as well. Higher Hf content substrates appear to need higher Pt content $\gamma+\gamma^{\prime}$ coatings to suppress internal Hf oxidation, Figure 4a. However, one difference between the 142 and N5 substrates is the higher S content in the former, Table I, which may have negatively impacted their oxidation performance.[46]

Some of the other attractive features of $\gamma+\gamma^{\prime}$ coatings are mechanical strength and CTE. The higher strength should limit fatigue problems. Of course, much more work is needed to understand the mechanical properties in this system. The relatively low CTE measured (Fig. 17) likely explains the good scale adhesion in this system. The thermal stress that drives scale spallation is a function of the CTE mismatch between the metal and scale.[47]

There are several concerns about these coatings:

(1) Substrate compatibility: Based on the results with 142 and N5 substrates, $\gamma+\gamma^{\prime}$ coatings are sensitive to the superalloy substrate composition, which is true to some degree for all bond coatings. However, aluminide coatings have lower solubility for many substrate elements, making them less sensitive than $\gamma+\gamma^{\prime}$ coatings. Thus, $\gamma+\gamma^{\prime}$ coatings may not be suitable for certain superalloy compositions and conditions.

(2) Pt interdiffusion: Initially it was hoped that these coatings offered higher temperature capability than other coatings. However, based on the Pt interdiffusion observed, Figure 6, this appears somewhat unlikely.[8] Although the Al content does not decrease significantly, as it does for $\beta$ and MCrAlY coatings, the loss of $\mathrm{Pt}$ is an issue for retaining the oxidation resistance with such a low Al content. An additional concern is the disruption of the substrate $\gamma+\gamma^{\prime}$ microstructure, which could reduce the superalloy creep strength. Particularly for thin-walled airfoils, this may be a concern that needs to be further evaluated.

(3) Ni-rich spinel oxide formation: The transient formation of $\mathrm{Ni}$ rich oxides may be a concern for TBC processing where a strong $\mathrm{Al}_{2} \mathrm{O}_{3}$-YSZ bond is desired. Initially oxidizing with low $\mathrm{O}_{2}$ partial pressures can suppress the formation of Ni-rich oxides by making them thermodynamically unstable.[48] However, in service spinel 


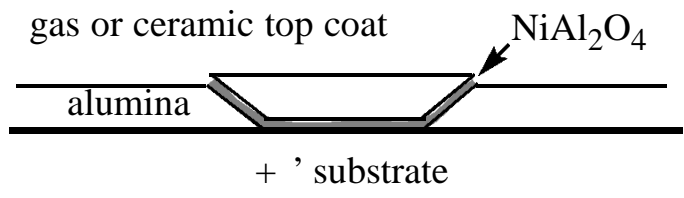

Figure 18. Schematic for scale spallation with a $\gamma+\gamma^{\prime}$ coating or alloy. When the alumina scale spalls, if the substrate initially forms a Ni-rich oxide, the protective oxide layer will be degraded.

formation, particularly in the presence of water vapor, could reduce the TBC lifetime. When the scale reaches a critical thickness, spallation is observed for all alumina-forming alloys. Figure 18 shows schematically a wedge-type failure.[47] For a typical alumina-forming substrate, the new oxide formed in the cracks would be alumina and the scale would heal to some degree. However, a spinel-forming substrate would fill the cracks with spinel, creating a permanent defect in the scale that would allow more rapid transport thereby increasing the scale growth rate and thus increasing the $\mathrm{Al}$ consumption rate. A similar model was proposed for the poor oxidation resistance of $\mathrm{Ni}_{3} \mathrm{Al}$ alloys.[38] Such a mechanism likely occurs for the failure of any Al-depleted, Ni-base alumina-forming coating, accounting for the formation of Ni-rich oxides at failure.[35,36] This mechanism could reduce the anticipated lifetime for these coatings.

(4) Secondary processing: Some of these concerns may be addressed by a secondary processing step where Al, Hf or other elements are added to a $\gamma+\gamma$ ' coating. However, adding steps to the coating process will increase the cost and remove one of the attractive features of these coatings.

\section{Summary}

In order to assess the performance of $\gamma+\gamma^{\prime}$ coatings for future power generation applications, $\gamma+\gamma^{\prime}$ coatings and model alloys have been examined. Several factors affecting the fabrication and performance of coatings have been evaluated on N5 and 142 substrates. The performance of $\gamma+\gamma^{\prime}$ coatings was much better on N5 substrates in both dry $\mathrm{O}_{2}$ and with $\mathrm{H}_{2} \mathrm{O}$ in the environment. This result needs to be further studied with different coating $\mathrm{Pt}$ contents and substrate $\mathrm{S}$ contents. Extensive Pt interdiffusion and substrate $\mathrm{Al}$ loss was observed after thermal cycling a $\gamma+\gamma^{\prime}$ coating on $\mathrm{N} 5$ at $1150^{\circ} \mathrm{C}$.

The oxidation performance of model $\gamma+\gamma^{\prime}$ alloys also was examined. Replacing Pt with Pd or Ir did not appear to be promising. A Pt content of $\sim 10 \%$ was needed to limit the amount of Ni-rich oxide formed at $1000^{\circ} \mathrm{C}$. However, even with $30 \% \mathrm{Pt}$, a transient, Ni-rich oxide formed at $1200^{\circ} \mathrm{C}$. The yield stress of a $\gamma+\gamma^{\prime}$ alloy was significantly higher than $\beta$-NiAl or MCrAlY specimens. The thermal expansion was similar to other $\mathrm{Ni}-\mathrm{Al}$ compositions.

The current assessment of $\gamma+\gamma^{\prime}$ coatings is that they offer several attractive features including oxidation resistance and mechanical properties. Several concerns need to be addressed including the apparent sensitivity to superalloy composition, the effect of $\mathrm{Pt}$ interdiffusion in the substrate, the formation of $\mathrm{Ni}$-rich spinel oxide, and the potential need for secondary processing steps.

\section{Acknowledgements}

The authors would like to thank G. Garner, J. Moser, H. Longmire, L. Walker, K. M. Cooley and D. W. Coffey at ORNLfor assistance with the experimental work. M. P. Brady and P. F. Tortorelli at ORNL provided helpful comments on the manuscript. Research sponsored at ORNL by the U.S. Department of Energy, Office of Coal and Power R\&D, Office of Fossil Energy, (R. Dennis program manager) under contract DE-AC05-00OR22725 with UTBattelle, LLC. At TTU, a portion of this work was funded by the National Science Foundation GOALI Program, Grant 0504566.

\section{References}

1. K. Bouhanek, O. A. Adesanya, F. H. Stott, P. Skeldon, D. G. Lees and G. C. Wood, "High Temperature Oxidation of Thermal Barrier Coating Systems on RR3000 Substrates: Pt Aluminide Bond Coats," Mater. Sci. Forum, 369-372 (2001), 615-622.

2. B. Gleeson, W.Wang, S. Hayashi and D. Sordelet, "Effects of Platinum on the Interdiffusion and Oxidation Behavior of Ni-AlBased Alloys," Mater. Sci. Forum, 461-464 (2004), 213-222.

3. B. A. Pint, J. A. Haynes, K. L. More and I. G. Wright, "The Use of Model Alloys to Understand and Improve the Performance of Pt-modified Aluminide Coatings," Superalloys 2004, ed. K. A. Green, et al. (Warrendale, PA: TMS, 2004), 597-606.

4. Y. Zhang, J. A. Haynes, B. A. Pint and I. G. Wright, "A Platinum-Enriched $\gamma+\gamma$ ' Two-Phase Bond Coat on Ni-Base Superalloys," Surf. Coat. Tech., 200 (2005), 1259-1263

5. V. Deodeshmukh, N. Mu, B. Li and B. Gleeson, "Hot Corrosion and Oxidation Behavior of a Novel Pt+Hf-modified $\gamma$ '$\mathrm{Ni}_{3} \mathrm{Al}+\gamma-\mathrm{Ni}$-based coating," Surf. Coat. Tech., 201 (2006)3836-40.

6. T. Izumi and B. Gleeson, "Oxidation Behavior of Pt plus Hfmodified $\gamma$-Ni plus $\gamma^{\prime}-\mathrm{Ni}_{3} \mathrm{Al}$ Alloys," Mater. Sci, Forum, 522-523 (2005), 221-228.

7. T. Izumi, N. Mu, L. Zhang and B. Gleeson, "Effects of Targeted $\gamma-\mathrm{Ni}+\gamma^{\prime}-\mathrm{Ni}_{3} \mathrm{Al}$-Based Coating Compositions on Oxidation Behavior," Surf. Coat. Tech., 202 (2007), 628-631.

8. J. R. Nicholls, "Advances in Coating Design for HighPerformance Gas Turbines," MRS Bull., 28 (2003), 659-670.

9. J. A. Haynes, B. A. Pint, Y. Zhang and I. G. Wright, "Comparison of the Cyclic Oxidation Behavior of $\beta$-NiAl, $\beta$ NiPtAl and $\gamma+\gamma$ ' NiPtAl Coatings on Various Superalloys," Surf. Coat. Tech., 202 (2007) 730-734.

10. P. Chiesa, S. Consonni, T. Kreutz and R. Williams, "CoProduction of Hydrogen, Electricity and $\mathrm{CO}_{2}$ from Coal with Commercially Ready Technology. Part A: Performance and Emissions," Inter. J. Hydrogen Energy, 30 (2005), 747-767.

11. R. A. Miller, "Life Modeling of Thermal Barrier Coatings for Aircraft Gas Turbine Engines," J. Eng. Gas Turb. \& Power, 111 (1989), 301-5.

12. S. M. Meier, D. M. Nissley, K. D. Sheffler and T. A. Cruse, "Thermal Barrier Coating Life Prediction Model Development," J. Eng. Gas Turb. \& Power, 114 (1992), 258-63.

13. B. A. Pint, P. F. Tortorelli and I. G. Wright, "Effect of Cycle Frequency on High Temperature Oxidation Behavior of AluminaForming Alloys," Oxid. Met., 58 (2002), 73-101.

14. L. A. Gianuzzi and F. A. Stevie, "A Review of Focused Ion 
Beam Milling Techniques for TEM Specimen Preparation," Micron, 30(3) (1999), 197-204.

15. Y. Zhang, D. A. Ballard, J. P. Stacy, B. A. Pint and J. A. Haynes, "Synthesis and Oxidation Behavior of Platinum-Enriched $\gamma+\gamma$ ' Bond Coatings on Ni-Base Superalloys," Surf. Coat. Tech., 201 (2006), 3857-3861.

16. J. P. Stacy, Y. Zhang, B. A. Pint, J. A. Haynes, B. T. Hazel and B. A. Nagaraj, "Synthesis and Oxidation Performance of AlEnriched $\gamma+\gamma$ ' Coatings on Ni-Based Superalloys Via Secondary Aluminizing," Surf. Coat. Tech., 202 (2007), 632-636.

17. Y. Zhang, W.Y. Lee, J. A. Haynes, I. G. Wright, B. A. Pint, K. M. Cooley and P. K. Liaw, "Synthesis and Cyclic Oxidation Behavior of a (Ni,Pt)Al Coating on a Desulfurized Ni-base Superalloy," Met. Mater. Trans., 30A(1999), 2679-87.

18. R. C. Reed, private communication (2006).

19. D. S. Rickerby, S. R. Bell and R. G. Wing, U.S. Patents 5,667,663 (1997) and 5,981,091 (1999).

20. A. L. Purvis and B. M. Warnes, "The Effects of Pt Concentration on the Oxidation Resistance of Superalloys Coated with Single-Phase Pt Aluminide," Surf. Coat. Tech., 146-147 (2001), 1-6.

21. J. A. Haynes, B. A. Pint, Y. Zhang, K. M. Cooley, L. R. Walker and I. G. Wright, "The Effect of Pt Content on $\gamma+\gamma$ ' Diffusion Coatings," submitted to Surf. Coat. Tech.

22. E. Copland, "Partial Thermodynamic Properties of $\gamma^{\prime}-$ $(\mathrm{Ni}, \mathrm{Pt})_{3} \mathrm{Al}$ in the Ni-Al-Pt System," J. Phase Equil. Diff., 28 (2007), 38-48.

23. B. A. Pint, K. L. More and I. G. Wright, "The Oxidation Behavior of Low Al Ni-Pt-Al Cast Alloys," for submission to Oxidation of Metals.

24. B. A. Pint, J. A. Haynes, Y. Zhang, K. L. More and I. G. Wright "The Effect of Water Vapor on the Oxidation Behavior of Ni-Pt-Al Coatings and Alloys," Surf. Coat. Tech., 201 (2006), 3852-3856.

25. C. Leyens, K. Fritscher, R. Gehrling, M. Peters and W.A. Kaysser, "Oxide Scale Formation on an MCrAlY Coating in Various $\mathrm{H}_{2}-\mathrm{H}_{2} \mathrm{O}$ Atmospheres," Surf. Coat. Tech., 82 (1996), 13344.

26. R. Janakiraman, G. H. Meier and F. S. Pettit, "The Effect of Water Vapor on the Oxidation of Alloys that Developed Alumina Scales for Protection," Met. Mater. Trans., 30A(1999), 2905-2913.

27. K. Onal, M. C. Maris-Sida, G. H. Meier and F. S. Pettit, "Water Vapor Effects on the Cyclic Oxidation Resistance of Alumina-Forming Alloys," Mater.High Temp., 20 (2003),327-337.

28. M. C. Maris-Sida, G. H. Meier and F. S. Pettit, "Some Water Vapor Effects During the Oxidation of Alloys That Are $\alpha-\mathrm{Al}_{2} \mathrm{O}_{3}$ Formers," Met. Mater. Trans., 34A (2003), 2609-19.

29. E. J. Opila, "Volatility of Common Protective Oxides in HighTemperature Water Vapor: Current Understanding and Unanswered Questions," Mater. Sci. Forum, 461-464 (2004), 76574.

30. J. A. Haynes, B. A. Pint, W. D. Porter and I. G. Wright, "Comparison of Thermal Expansion and Oxidation Behavior of Various High-Temperature Coating Materials and Superalloys," Mater. High Temp., 21 (2004), 87-94.

31. G. C. Rybicki and J. L. Smialek, "Effect of the $\theta-\alpha-\mathrm{Al}_{2} \mathrm{O}_{3}$ Transformation on the Oxidation Behavior of $\beta-\mathrm{NiAl}+\mathrm{Zr}$," Oxid. Met., 31 (1989), 275-304.

32. J. Doychak, J.L. Smialek and T.E. Mitchell, "Transient
Oxidation of Single-Crystal $\beta$-NiAl," Met. Trans., 20A (1989), 499-518.

33. C. S. Giggins and F. S. Pettit, "Oxidation of Ni-Cr-Al Alloys Between $1000^{\circ}$ and $1200^{\circ} \mathrm{C}$," J. Electrochem. Soc., 118 (1971) 1782-90.

34. F. H. Stott, G. C. Wood and J. Stringer, "The Influence of Alloying Elements on the Development and Maintenance of Protective Scales," Oxid. Met., 44 (1995), 113-45.

35. B. C. Wu, E. Chang, C. H. Chao, and M. L. Tsai, "The Oxide Pegging Spallation Mechanism and Spalling Modes of $\mathrm{ZrO}_{2}$ $8 \mathrm{wt} \% \mathrm{Y}_{2} \mathrm{O}_{3} / \mathrm{Ni}-22 \mathrm{Cr}-10 \mathrm{Al}-1 \mathrm{Y}$ TBC's Under Various Operating Conditions," J. Mater. Sci., 25 (1990), 1112-9.

36. B. A. Pint, B. A. Nagaraj, and M. A. Rosenzweig, "Evaluation of TBC-Coated $\beta$-NiAl Substrates Without a Bond Coat," Elevated Temperature Coatings: Science and Technology II, eds. N. B. Dahorte, J. M. Hampikian, and J. J. Stiglich (Warrendale, PA: TMS, 1996) 163-74.

37. J. Doychak and M. Rühle, "TEM Studies of Oxidized NiAl and Ni3Al Cross Sections," Oxid. Met., 31 (1989), 431-452.

38. B. A. Pint, A. J. Garratt-Reed and L. W. Hobbs, "Analytical Electron Microscopy Study of the Breakdown of $\alpha-\mathrm{Al}_{2} \mathrm{O}_{3}$ Scales Formed on Oxide Dispersion Strengthened Alloys," Oxid. Met., 56 (2001), 119-145

39. B. A. Pint and J. H. Schneibel, "The Effect of Carbon and Reactive Element Dopants on Oxidation Lifetime of FeAl," Scripta Materialia, 52 (2005), 1199-1204.

40. B. A. Pint, "Experimental Observations in Support of the Dynamic Segregation Theory to Explain the Reactive Element Effect," Oxid. Met., 45 (1996), 1-37.

41. B.A. Pint, I.G. Wright, W.Y. Lee, Y. Zhang, K. Prüßner and K.B. Alexander, "Substrate and Bond Coat Compositions: Factors Affecting Alumina Scale Adhesion," Mater. Sci. Eng., 245 (1998), 201-211.

42. B. A. Pint, J. A. Haynes, K. L. More, I. G. Wright and C. Leyens, "Composition Effects on Aluminide Oxidation Performance: Objectives for Improved Bond Coats," Superalloys 2000, ed. T. M. Pollock, et al. (Warrendale, PA: TMS, 2000) 62938.

43. J. A. Haynes, B. A. Pint, K. L. More, Y. Zhang, and I. G. Wright, "Influence of Sulfur, Platinum and Hafnium on the Oxidation Behavior of CVD NiAl Bond Coatings," Oxid. Met., 58 (2002), 513-544.

44. R. Kartono and D. J. Young, "Effectiveness of Pt and Ir in Improving the Resistance of Ni-Al to Thermal Cycling in AirSteam Mixtures," Mater. Corr., in press (2008).

45. B. M. Warnes, "Reactive Element Modified Chemical Vapor Deposition Low Activity Platinum Aluminide Coatings," Surf. Coat. Tech., 146-147 (2001), 7-12.

46. J. L. Smialek, D. T. Jayne, J. C. Schaeffer and W. H. Murphy, "Effects of Hydrogen Annealing, Sulfur Segregation and Diffusion on the Cyclic Oxidation Resistance of Superalloys: A Review," Thin Solid Films, 253 (1994), 285-92.

47. H. E. Evans, "Stress Effects in High Temperature Oxidation of Metals," Int. Mater. Rev., 40 (1995), 1-40.

48. B. H. Kear, F. S. Pettit, D. E. Fornwalt and L. P. Lemaire, "On the Transient Oxidation of a Ni-25Cr-6Al Alloy," Oxid. Met., 3 (1971), 557-69. 